\title{
Antiviral prophylaxis in patients with solid tumours and haematological malignancies - update of the Guidelines of the Infectious Diseases Working Party (AGIHO) of the German Society for Hematology and Medical Oncology (DGHO)
}

\author{
Michael Sandherr $^{1}$ • Marcus Hentrich ${ }^{2} \cdot$ Marie von Lilienfeld-Toal $^{3}$ - Gero Massenkeil ${ }^{4}$. \\ Silke Neumann ${ }^{5}$ - Olaf Penack ${ }^{6} \cdot$ Lena Biehl $^{7,8} \cdot$ Oliver A. Cornely $^{7,9}$
}

Received: 24 April 2015 / Accepted: 6 July 2015 /Published online: 21 July 2015

(C) The Author(s) 2015. This article is published with open access at Springerlink.com

\begin{abstract}
Reactivation of viral infections is common in patients with solid tumour or haematological malignancy. Incidence and severity depend on the extent of cellular immunosuppression. Antiviral prophylaxis may be effective to prevent viral reactivation. In 2006, the Infectious Diseases Working Party of German Society for Hematology and Medical Oncology (DGHO) published guidelines for antiviral prophylaxis in these patient populations. Here, we present an update of these guidelines for patients with solid and haematological malignancies undergoing antineoplastic treatment but not
\end{abstract}

Michael Sandherr

michael.sandherr@web.de

1 Gemeinschaftspraxis für Hämatologie und Onkologie, Röntgenstr. 4, 82362 Weilheim, Germany

2 Klinik für Hämatologie, Onkologie und Palliativmedizin, Städtisches Klinikum Harlaching, München, Germany

3 Klinik für Innere Medizin II, Hämatologie und Internistische Onkologie, Universitätsklinikum Jena, Jena, Germany

4 Medizinischen Klinik II, Klinikum Gütersloh, Gütersloh, Germany

5 Ambulantes Onkologiezentrum Wolfsburg, Wolfsburg, Germany

6 Medizinische Klinik mit Schwerpunkt Hämatologie, Onkologie und Tumorimmunologie, Charité Universitäts medizin Berlin, Campus Virchow Klinikum, Berlin, Germany

7 Klinik I für Innere Medizin, Unklinik Köln, Köln, Germany

8 Deutsches Zentrum für Infektionsforschung (DZIF), partner site Bonn-Köln, Köln, Germany

9 Zentrum für Klinische Studien ZKS Köln, BMBF 01KN1106, Centrum für integrierte Onkologie CIO KölnBonn, Cologne Excellence Cluster on Cellular Stress Responses in Aging-Associated Diseases (CECAD), Medizinische Fakultät, Universität zu Köln, Köln, Germany allogeneic stem cell transplantation. Relevant literature for reactivation of different viruses (herpes simplex virus (HSV), varicella zoster virus (VZV), hepatitis B virus (HBV) and respiratory viruses) is discussed to provide evidence-based recommendations for clinicians taking care of this patient population. We recommend a risk-adapted approach with (val)acyclovir against HSV and VZV in patients treated with alemtuzumab, bortezomib or purine analogues. Seasonal vaccination against influenza is recommended for all patients with solid or haematological malignancies regardless of antineoplastic therapy. Hepatitis B screening is recommended in lymphoproliferative disorders, acute leukaemia, and breast cancer, and during treatment with monoclonal anti-B-cell antibodies, anthracyclines, steroids and in autologous stem cell transplantation. In those with a history of hepatitis B prophylactic lamivudine, entecavir or nucleotide analogues as adefovir are recommended to prevent reactivation.

Keywords Guideline · Antiviral prophylaxis · Hepatitis B · Cancer treatment

\section{Introduction}

The risk of patients with solid tumours or haematological malignancies to contract viral infections is relatively low. Viral diseases occur most likely as reactivation of latent infections with herpes simplex virus (HSV), varicella zoster virus (VZV) and hepatitis $B$ virus (HBV) being the most common viruses in these patients [1]. Apart from the setting of allogeneic stem cell transplantation, cytomegalovirus (CMV) and EpsteinBarr virus (EBV) play a subordinate role.

In recent years, the clinical relevance of viral infections of the respiratory tract has been increasingly recognized. Most 
viral infections are exogenous, primary infections. Influenza viruses are particularly important since patients with malignancies have an increased risk of contracting infections [2]. Moreover, an increased rate of secondary complications including bacterial pneumonia and fatal outcome has been observed [3].

The major risk factor for the occurrence of viral complications is the extent of cellular immunosuppression. The risk increases with the intensity and duration of T-cell suppression, as seen in the rate of viral complications during treatment with the T-cell antibody alemtuzumab. Severity and duration of neutropenia are of minor importance.

In 2006, the Infectious Diseases Working Party (AGIHO) of the German Society for Hematology and Medical Oncology (DGHO) published guidelines on antiviral prophylaxis in this patient population including recipients of allogeneic stem cell transplants [4]. The present aim of this guideline is to update the recommendations for patients with solid tumours and haematological malignancies. Recommendations for recipients of allogeneic stem cell transplants will be published separately and are not discussed here.

These guidelines have been prepared and composed by an expert panel from the AGIHO. Relevant literature published after 2006 was identified and reviewed using MEDLINE, CANCERLIT and the Cochrane library. Recent study results presented at major meetings in this field, including ASH, EHA, ASCO, ESMO, ECCMID or ICAAC, were additionally taken into account. The results were further discussed and finally approved by the assembly of the members of the AGIHO. The present article summarizes the development and rationale of the recommendations.

The aim of these guidelines is to provide physicians with evidence-based recommendations for the prevention of viral reactivations and primary viral infections in patients with solid tumours and haematological malignancies. In contrast to other published guidelines [5, 6], its relevance for a day-by-day use in the clinical setting is based on the evidence of recommendations as proposed by the Infectious Disease Society of America (IDSA) (see Table 1) [7]. The risk of viral complications and respective preventive strategies were determined depending on the underlying disease and specific therapies, i.e. chemotherapy with or without administration of monoclonal antibodies.

\section{Patient populations}

\section{Conventionally dosed chemotherapy in solid tumours and haematological malignancies}

Patients treated with conventionally dosed chemotherapy for their malignancy are at low risk for clinically relevant virus reactivations. The degree of cellular immunosuppression in patients with solid tumours is very limited. Furthermore, the majority of chemotherapeutics does not lead to a substantial suppression of T-cell function. Thus, the reactivation of HSV, VZV [8], EBV or CMV (30) constitutes a rare event in this patient population and does not require prophylaxis.

In contrast, the risk of primary viral infections of the upper respiratory tract is notably increased in patients with an active malignancy, with infections due to influenza, parainfluenza and respiratory syncytial virus (RSV) being the most clinically relevant [9-11]. As there are no effective prophylactic drugs, the instruction and performance of general hygiene measures represent an important prophylactic action [12, 13]. Despite the high variability in the response to the attenuated influenza vaccine in these patients [14], the influenza vaccine is recommended in patients with an active malignancy undergoing chemotherapy [15].

Induction and consolidation therapy in acute leukaemia patients results in a high risk for infectious complications. The occurrence of severe and persistent neutropenia with neutrophil counts below $500 / \mu$ l or even $100 / \mu 1$ leads to an increased risk for febrile complications, mostly due to bacterial or fungal infections. Most viral infections during neutropenia are due to HSV [16]. A severe mucositis can impair the mucosal barrier leading to an increased risk for bacterial infections. Thus, the continuation of curative chemotherapy can be delayed. In addition, mucositis due to viruses results in significant deterioration of the patient's general condition by causing severe pain, reduction of nutritional intake and cachexia. These complications are good reasons to prevent HSV reactivation. However, several studies could not prove a significant effect of acyclovir prophylaxis on the time and duration of antibiotic treatment, the number of febrile days, the rate of bloodstream infections and other opportunistic infections or mortality [17-19]. Accordingly, there is not enough evidence from randomized trials on antiviral prophylaxis for HSV in patients with acute leukaemia to establish a strong recommendation [20]. In contrast, the vaccination for influenza is recommended for all patients with acute leukaemia after intensive chemotherapy and for acute lymphoblastic leukaemia during the course of maintenance treatment [21].

Reactivation of hepatitis B virus infection is rather common in patients with solid tumours and haematological malignancies undergoing conventional chemotherapy and constitutes a serious complication for those patients [22-25]. In hepatitis B surface antigen (HBsAg) positive patients, the rate of reactivation is approximately $20-50 \%$, resulting in fulminant hepatitis and a high lethality in some cases. The risk is especially high in patients with malignant lymphoma and those undergoing treatment with anthracyclines [26, 27] or higher doses of steroids (10-20 mg prednisone daily or equivalent $\geq 4$ weeks) $[28,29]$. Primary antiviral prophylaxis with nucleoside analogues lamivudine and entecavir as well as 
Table 1 Infectious Diseases Society of America - United States Public Health Service grading system for ranking recommendations

\begin{tabular}{ll}
\hline Category, grade & Definition \\
\hline Strength of recommendation & \\
A & Good evidence to support a recommendation for use \\
B & Moderate evidence to support a recommendation for use \\
C & Poor evidence to support a recommendation \\
D & Moderate evidence to support a recommendation against use \\
E & Good evidence to support a recommendation against use \\
Quality of evidence & \\
I & Evidence from $\geq 1$ properly randomized, controlled trial \\
II & Evidence from $\geq 1$ well-designed clinical trial, without randomisation; \\
& from cohort or case-controlled analytic studies (preferably from $>1$ centre); \\
& from multiple time-series; or from dramatic results from uncontrolled \\
& experiments \\
III & Evidence from opinions of respected authorities, based on clinical experience, \\
& descriptive studies, or reports of expert committees \\
\hline
\end{tabular}

nucleotide analogues adefovir and tenofovir are effective in the prevention of reactivation in patients with evidence of previous hepatitis B infection. Prophylaxis was associated with an $87 \%$ relative risk reduction of reactivation [30] and also prevents fulminant hepatitis effectively [31]. Successful prophylaxis is of high prognostic value in patients with a curable underlying disease; patients can continue chemotherapy in time without interruption or dose reduction due to hepatitis.

Mono- and combination therapies with purine analogues like fludarabine or pentostatin result in a sustainable cellular immunosuppression and an increased risk for opportunistic infections $[32,33]$. In the setting of first-line treatment, reactivations of VZV and HSV are rarely observed. Thus, primary prophylaxis with acyclovir cannot be recommended in this patient population.

In the presence of clinical risk factors including CD4+ cell count $<50 / \mu$, long-term treatment with steroids, persistent neutropenia, age more than 65 years or an advanced stage of underlying disease, antiviral prophylaxis can be reasonable [34]. Results from newer studies since 2006 do not substantially change the recommendations regarding risk and prophylactic strategy with acyclovir or valacyclovir to prevent VZV or HSV reactivation.

In conclusion, no general recommendation regarding prophylactic medication for HSV, EBV or CMV in patients with solid tumours and haematological malignancies undergoing conventionally dosed chemotherapy can be given (see Table 2). The risk of viral reactivation is low due to only limited cellular immunosuppression, and evidence from randomized trials is missing. This is different for influenza and HBV; for these viruses, evidence-based strategies to prevent primary infection (influenza) or reactivation of latent infection (HBV) exist (see Table 2 and Fig. 1).

\section{Monoclonal antibodies}

Administration of monoclonal antibodies has become an integral part of treating malignancies. In the treatment of solid tumours, antibodies against growth factors of angiogenesis and against growth receptors like the EGF-receptor are well established. Examples include the combination of trastuzumab, bevacizumab or cetuximab with classical chemotherapy in the treatment of breast and colorectal cancer.

In lymphoproliferative diseases, targeted therapy against CD20 and-more recently-CD30 is widespread. The administration of rituximab, an anti-CD20 antibody, represents the basis of the treatment of B-cell lymphoma [35, 36]. Second generation antibodies like ofatumumab or obinutuzumab are about to be integrated in everyday clinical practice.

This treatment leads to a sustained B-cell depletion and, thus, increases the risk of viral reactivations. Most clinically relevant in this setting is the reactivation of $\mathrm{HBV}$, which can occur in up to $50 \%$ of patients with previous hepatitis $\mathrm{B}$ [37-40]. Reactivations of HSV, VZV, CMV, EBV and other viruses are more infrequent. The substantial cellular immunosuppression caused by the anti-CD20 therapy is also evident in associated cases of progressive multifocal leukencephalopathy as a result of JC virus reactivation [41].

On the basis of current evidence, there is no rationale for prophylaxis against HSV, VZV, EBV or CMV during B-cell antibody treatment. Nevertheless, particular attention should be paid to clinical signs of viral reactivation, as a wide variety of atypical pathogens can cause severe infections during the course of treatment. To prevent influenza infection, vaccination is recommended. Despite the predominantly inadequate immune response under treatment with B-cell antibodies, some results indicate reduced severity of influenza infections after vaccination [42, 43]. 
Table 2 Evidence-based recommendations for antiviral prophylaxis in patients with solid tumours and haematological malignancies except hepatitis B

\begin{tabular}{|c|c|c|c|c|c|c|}
\hline & Chemotherapy & Rituximab & Alemtuzumab & Proteasome inhibitors & Purine analogues & Autologous SCT \\
\hline $\mathrm{HSV} / \mathrm{VZV}$ & None (CII) & None (CII) & Acyclovir (AII) & Acyclovir (AII) & Acyclovir $^{\mathrm{a}}$ (AII) & None (CII) \\
\hline Influenza & Vaccination (AII) & Vaccination (BIII) & Vaccination (BIII) & Vaccination (AIII) & Vaccination (BIII) & Vaccination (BIII) \\
\hline CMV & None (CII) & None (CII) & None (BII) & None (CIII) & None (CIII) & None (CII) \\
\hline EBV & None (EIII) & None (EIII) & None (EIII) & None (EIII) & None (EIII) & None (EIII) \\
\hline Resp. viruses adenovirus & None (CII) & None (CII) & None (CII) & None (CII) & None (CII) & None (CII) \\
\hline $\mathrm{HCV}$ & None (CII) & None (CII) & None (CII) & None (CII) & None (CII) & None (CII) \\
\hline
\end{tabular}

${ }^{a}$ In the presence of risk factors: second-line therapy, prolonged treatment with steroids, $\mathrm{CD} 4$ count $<50 / \mu 1$, age $>65$ years, neutrophil count $<1000 / \mu$

Additionally, all patients receiving B-cell antibodies should be screened for chronic hepatitis B as a clinical standard [44]. This recommendation has been expressed in guidelines of different societies [45-52]. The cost-effectiveness of this strategy has recently been demonstrated in patients receiving RCHOP (rituximab plus cyclophosphamide, doxorubicin, vincristine and prednisone) for malignant lymphoma [53].

The algorithm of screening and antiviral prophylaxis for hepatitis B is explained in the chapter on antiviral substances and in Fig. 1.

The administration of anti-CD30 antibodies linked with a cytostatic (i.e. brentuximab vedotin) is an established alternative in the therapy of relapsed Hodgkin's lymphoma and in CD30-positive anaplastic large-cell lymphoma [54]. There are reports of an increased incidence of opportunistic infections; viral reactivations, however, are not a major concern. On the basis of already existing data, no general recommendation on antiviral prophylaxis can be made.

Currently, alemtuzumab, an anti-CD52 antibody, is only rarely used for treatment of CLL. Several studies have shown that the incidence of reactivations of HSV, VZV and CMV is considerably high [55]. Therefore, prophylaxis with acyclovir for $\mathrm{HSV}$ and VZV as well as monitoring of CMV reactivation by PCR or detection of the early antigen in peripheral blood has become standard. No changes apply to the recommendations of 2006 [4].

\section{Proteasome inhibitors}

Bortezomib is a proteasome inhibitor and a standard treatment for multiple myeloma. The substance is usually given in combination with dexamethasone or with classical cytostatics. It can be used both in primary therapy and for relapsed disease. Another molecule of this class is carfilzomib, a secondgeneration proteasome inhibitor, which has recently been approved by the Food and Drug Administration (FDA) [56].

The APEX study showed an increased VZV reactivation rate in patients receiving bortezomib [57]. These reactivations can be effectively prevented by low-dose acyclovir prophylaxis, as reported in several phase II trials and retrospective analyses [58-61]. However, to date, there are no randomized phase III trials addressing this question. On the basis of the given results, a recommendation for VZV prophylaxis by lowdose acyclovir or valacyclovir can be made. Further prophylactic agents are not indicated in this setting.
Fig. 1 Algorithm for prophylaxis of $\mathrm{HBV}$ reactivation

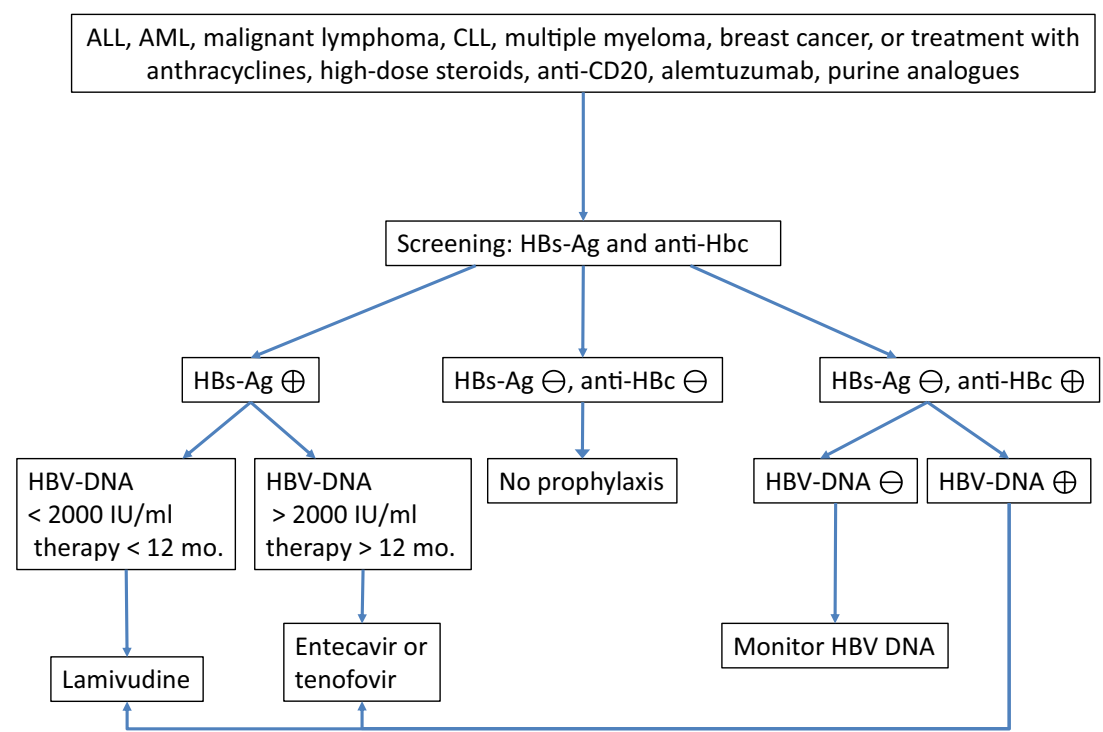


Patients with multiple myeloma present with marked immune deficiency that - as compared to other lymphoproliferative diseases - can be accompanied by a distinct antibody deficiency syndrome. Therefore, immunization is an important measure in preventing infections in this patient population [56]. Seasonal influenza vaccination is indicated for patients with multiple myeloma both with or without treatment with proteasome inhibitors [62].

\section{Autologous stem cell transplantation}

The risk of opportunistic infections after autologous stem cell transplantation (SCT) correlates with the immune reconstitution. As T-cell depleted grafts are no longer used, the cellular immune deficiency is usually mild. However, it correlates with the extent of pre-treatment and the remission state of the underlying disease. Pre-treatment with high dose steroids or a transplantation after the second or higher relapse lead to marked cellular immunosuppression and thus to an increased risk for viral reactivations. Antiviral prophylaxis may thus be helpful in individual cases.

Reactivations of HSV and VZV leading to mucocutaneous infections are paramount after autologous SCT [63]. HSV infections may occur along with mucositis after high dose chemotherapy until the regeneration of the granulocytes. VZV reactivation is more frequent after reconstitution of granulopoesis until day 100 after transplantation. Reported incidences differ and vary from 8 to $20 \%$ [64].

No new evidence-based data addressing this topic has been generated since 2006. In particular, no randomized trials on antiviral prophylaxis have been conducted. As a result, the recommendations of this guideline regarding antiviral prophylaxis after autologous SCT do not differ from those published previously [4]. General administration of acyclovir or valacyclovir for the prophylaxis of HSV or VZV reactivation is not recommended [20]. Such prophylaxis may depend on an individualized risk assessment per patient. Relevant factors for this include the extent of pre-treatment, the remission state at the time of transplantation, comorbidities, age, previous infections during the course of the disease and CD4+ count. However, no controlled randomized studies have been conducted to evaluate the efficacy of such an individualized approach.

The risk of CMV reactivation after autologous SCT without T-cell depletion is very low [65]. There is no rationale for prophylaxis.

Analogous to previously described clinical scenarios, there is an indication for HBV prophylaxis in patients with chronic hepatitis B. No changes were applied to the recommendations of 2006 - including the recommendation for the seasonal influenza vaccination $[21,66]$.

\section{Small molecules and signal transduction inhibitors}

The principle of signal transduction inhibition is an inherent part of modern tumour therapy today. Examples include mTOR inhibitors (e.g. everolimus) or interferences in the signal transduction of EGFR- or JAK2-pathways. A promising approach is seen in molecules, which interfere in the signal transduction of B-cell receptors (e.g. ibrutinib) and therefore present an attractive therapeutic option for B-CLL and B-cell lymphoma [67, 68]. Humoral as well as cellular immunosuppression may be common in patients treated with these agents, especially in those who are heavily pretreated. Therefore, antiviral prophylaxis may be indicated on an individual risk basis.

There are a growing number of reports on increased rates of opportunistic infections under this treatment [69]. However, in the COMFORT II trial, which compared the efficacy of ruxolitinib with the best available treatment in patients with myelfibrosis, the incidence of infections decreased over time without focus on reactivation of viral infections [70]. Wang et al. report similar results for a long-term follow-up of treatment with ibrutinib in patients with mantle-cell lymphoma [71]. Regarding reactivation of HBV, prophylaxis with lamivudine is an effective strategy to prevent reactivation [72].

An evidence-based recommendation for antiviral prophylaxis, thus, cannot be generated.

\section{Prophylactic treatment}

\section{Herpes simplex virus and varicella zoster virus}

The unaltered standard in the prophylaxis of HSV and $\mathrm{VZV}$ is acyclovir $400 \mathrm{mg}$ tid or qid or valacyclovir $500 \mathrm{mg}$ bid or tid [73]. Superiority of one of the two drugs could not yet be demonstrated $[74,75]$. Treatment should be initiated during the first week of antineoplastic therapy and continued beyond the end of therapy. So far, the best duration of prophylaxis could not be determined. We recommend monitoring CD4+ T-cell levels and the continuation of antiviral prophylaxis until the count is above 200/ $\mathrm{l}$. However, there are no randomized trials for this strategy.

Regarding prophylaxis of VZV during therapy with proteasome inhibitors, a lower dose of acyclovir or valacyclovir has shown to be effective. Dosages as low as $200-400 \mathrm{mg}$ for acyclovir or $500 \mathrm{mg}$ for valacyclovir daily or bid were successfully used [54-57]. Randomized trials comparing the different dosages, however, do not exist, and the risk of acyclovir resistance by using low doses has not been assessed yet. 


\section{Influenza viruses}

Seasonal vaccination against influenza can be recommended for all patients with solid tumours or haematological malignancies regardless of antineoplastic therapy [13, 21, 62, 76, 77]. Despite reduced immunological competence, there is evidence showing that $70-80 \%$ of patients with malignancies exhibit seroconversion after a vaccination [78, 79].

Patients with malignant lymphoma or multiple myeloma show a reduced response in comparison to patients with solid tumours [80]. Hence, a second vaccination can be reasonable in this patient population. According to the results of the VACANCE trial, the rate of seroconversion in patients with solid tumours was increased from 44 to $73 \%$ after a second administration of influenza vaccine [81]. Yet the optimal timing of a second vaccination-especially during ongoing tumour therapy - is unclear. Some results suggest a better effectiveness when administering the vaccination directly after chemotherapy instead of shortly before the next cycle [14].

In addition, vaccination of healthcare workers as well as family and household members is of particular importance to reduce influenza virus circulation and the risk of infection.

\section{Hepatitis B virus}

The risk of HBV reactivation during chemo- or immunotherapy is sufficiently documented in the literature [82]. HBV reactivation is of clinical relevance due to the high associated morbidity and lethality [83]. Reactivations have been described in all patients with a history of hepatitis B (that is, anti-HBc positive) regardless of the serological constellation (presence or absence of HB-antigens or anti-HBs) [84].

The incidence of reactivation varies in different patient populations [24]. In patients with solid tumours, the reactivation rate of HBV was reported to be below $1 \%$ [85]. Administration of anthracyclines is a negative prognostic factor in these patients $[26,27]$. On the other hand, HBV reactivation occurs in 30-50\% of patients with malignant lymphoma [86], with even higher rates during treatment with rituximab [40, 44]

In conclusion, the following clinical risk factors are associated with an increased risk of HBV reactivation:

- Treatment with anthracyclines

- Treatment with steroids: $>10-20 \mathrm{mg}$ prednisone daily or equivalent for $\geq 4$ weeks

- Treatment with monoclonal antibodies (rituximab, obinutuzumab, ofatumomab, alemtuzumab)

- Breast cancer as underlying disease

- Malignant lymphoma as underlying disease

Preemptive treatment with lamivudine, entecavir or nucleotide analogues as adefovir is standard in the prophylaxis of
HBV reactivation [4, 45, 87]. This preemptive measure, however, requires the evidence of a previous infection. Therefore, patients with haematological malignancies or patients with solid tumours before planned tumour therapy should undergo a screening on HBV infection. To date, it remains unclear whether a general screening of all patients is needed.

We favour a risk-adapted approach and recommend HBV screening in patients with malignant lymphoma, multiple myeloma, CLL, AML, ALL and breast cancer, as well as patients planned for therapy with monoclonal B-cell antibodies, alemtuzumab, chemotherapy protocols based on the use of anthracyclines, higher doses of steroids and those undergoing autologous SCT (AII). In this patient population, tests for HBs-Ag and anti-HBc antibodies should be performed.

In case of HBsAg negativity and anti-HBc antibody negativity, antiviral prophylaxis is not indicated and immunisation should be considered. Patients with a negative HBsAg and a positive anti-HBc antibody test should be tested for HBV DNA. Those with a positive viral load should receive prophylaxis while those with a negative PCR should be screened for reactivation on a regular basis [45] (AIII). So far, the optimal approach in this risk group is not defined. Depending on the intensity of immunosuppression, monitoring should be repeated every 1-3 months. In patients who receive treatment with a particularly high risk of $\mathrm{HBV}$ reactivation (e.g. anti-CD20 targeted therapy), antiviral prophylaxis regardless of $\mathrm{HBV}$ load should be considered.

In case of $\mathrm{HBsAg}$ positivity, the quantification of $\mathrm{HBV}$ DNA may determine the agent for antiviral prophylaxis (AI). Prophylactic treatment should be started together with the immunosuppressive therapy. While there are not randomized trials investigating the optimal duration of prophylaxis, reactivations have been described after the end of antineoplastic therapy. Thus, antiviral prophylaxis should be continued for 6-12 months after the completion of antineoplastic therapy (AII). The question of the most suitable antiviral drug for prophylaxis in this patient population is still unanswered. Most data on effectiveness exists for lamivudine. However, there are a few randomized trials with newer substances such as entecavir, adefovir or tenofovir [88]. Arguments for the latter include a higher antiviral potency and a lower risk of resistance development, which otherwise is substantially increasing after 12 months of treatment with lamivudine.

We suggest a risk-adapted approach in accordance with other recently published guidelines [30] (AIII). Prophylaxis with lamivudine is appropriate in short-term cancer treatment of approximately 4-6 months duration or in patients with a viral load below $2000 \mathrm{IU} / \mathrm{ml}$, which is associated with a low risk of disease (42). In sustained immunosuppression for more than 12 months, i.e. in rituximab maintenance therapy, or in case of a high viral load above $2000 \mathrm{IU} / \mathrm{ml}$, we recommend applying substances with a higher antiviral potency like entecavir or tenofovir (42) (see Fig. 1). 


\section{Cytomegalovirus}

In the above-described patient populations, there is no evidence for CMV prophylaxis. Serological monitoring of CMV reactivation by testing for early antigen or using PCR in peripheral blood is obligatory during treatment with alemtuzumab. It can be indicated in certain constellations with increased risk in patients undergoing autologous SCT. In principle, PCR is to be preferred due to its higher reliability not depending on the neutrophil count.

\section{Epstein-Barr virus}

Reactivation of EBV is rare in this patient population. Prophylaxis is not recommended.

\section{Respiratory viruses - other than influenza virus and adenovirus}

Patients with solid tumours or haematological malignancies have an increased risk for infections of the upper respiratory tract regardless of their tumour therapy. Usually these are primary infections. Therefore, patients should be monitored closely for clinical signs of infection. There is no indication for antiviral prophylaxis. However, patients with evidence of infection with respiratory viruses should be isolated to protect other patients from contracting the disease.

\section{Hepatitis C virus}

Hepatitis C (HCV) infection does not constitute a contraindication for therapy in these patients including those undergoing autologous SCT. Standard cancer treatment in HCV positive patients yields similar disease-free survival and overall survival rates compared to those who are HCV negative [89]. However, we recommend consultation of a hepatologist while setting up the cancer treatment strategy. First, HCV infection is associated with increased hepatic toxicity during chemotherapy, and second, it might be appropriate to treat the viral infection simultaneously since the availability of interferon-free anti-HCV therapy [90]. But in conclusion, at this moment, no reasonable evidence-based preventive measure exists.

\section{Conclusions}

Patients with solid tumours and haematological malignancies have - to different degrees - an increased risk for reactivation or primary acquisition of viral infections. The risk correlates with the intensity of cellular immunosuppression and, thus, with the type of therapy. Depending on this risk, evidencebased prophylaxis is indicated. This applies in particular to
HBV reactivation, herpes zoster and primary infections with influenza virus.

Conflict of interest MS has no conflicts of interest to declare.

MH served on the speakers' bureau for Gilead Sciences and MSD and received travel grants from Gilead Sciences, MSD and Pfizer.

MvLT has served at the speaker's bureau of MSD, Gilead, Celgene, Janssen Cilag and is a consultant to MSD.

GM has served at the speakers' bureau of Shire and Genzyme.

SN has no conflicts of interest to declare.

OP has received research funding from Bio Rad, Fresenius biotech, Gentium, Genzyme, Gilead and Pierre Fabre, is a consultant to MSD and has received lecture honoraria/travel grants from Astellas, Gilead, Pfizer and MSD.

LMB is supported by the German centre for Infection Research (DZIF). LMB has served at the speakers' bureau of Astellas and MSD.

OAC is supported by the German Federal Ministry of Research and Education (BMBF grant 01KN1106); has received research grants from $3 \mathrm{M}$, Actelion, Astellas, AstraZeneca, Basilea, Bayer, Celgene, Cubist/ Optimer, Genzyme, Gilead, GSK, Merck/MSD, Miltenyi, Pfizer, Quintiles, Shionogi and ViroPharma; is a consultant to $3 \mathrm{M}$, Astellas, AstraZeneca, Basilea, Cidara, Cubist/Optimer, Da Volterra, Daiichi Sankyo, F2G, Genentech, Gilead, GSK, Merck/MSD, Merck Serono, Pfizer, Rempex, Sanofi Pasteur, Summit and Vifor; and received lecture honoraria from Astellas, Gilead, Merck/MSD and Pfizer.

Open Access This article is distributed under the terms of the Creative Commons Attribution 4.0 International License (http:// creativecommons.org/licenses/by/4.0/), which permits unrestricted use, distribution, and reproduction in any medium, provided you give appropriate credit to the original author(s) and the source, provide a link to the Creative Commons license, and indicate if changes were made.

\section{References}

1. Angarone M (2011) Epidemiology and prevention of viral infections in patients with hematologic malignancies. Infect Disord Drug Targets 11:27-33

2. Kunisaki KM, Janoff EN (2009) Influenza in immunosuppressed populations: a review of infection frequency, morbidity, mortality, and vaccine responses. Lancet Infect Dis 9:493-504

3. Hajjar LA, Mauad T, Galas FR et al (2010) Severe novel influenza A (H1N1) infection in cancer patients. Ann Onco 21:2333-2341

4. Sandherr M, Einsele H, Hebart $\mathrm{H}$ et al (2006) Antiviral prophylaxis in patients with haematological malignancies and solid tumours: Guidelines of the Infectious Diseases Working Party (AGIHO) of the German Society for Hematology and Oncology (DGHO). Ann Oncol 17:1051-1059

5. Baden LR, Bensinger W, Angarone M et al (2012) Prevention and treatment of cancer-related infections. J Natl Compr Cancer Netw 10:1412-1445

6. Flowers CR, Seidenfeld J, Bow EJ et al (2013) Antimicrobial prophylaxis and outpatient management of fever and neutropenia in adults treated for malignancy: American Society of Clinical Oncology clinical practice guideline. J Clin Oncol Off J Am Soc Clin Oncol 31:794-810

7. Kish MA (2001) Guide to development of practice guidelines. Clin Infect Dis 32:851-854

8. Kim ST, Park KH, Oh SC et al (2012) Varicella zoster virus infection during chemotherapy in solid cancer patients. Oncology 82: $126-130$ 
9. Hicks KL, Chemaly RF, Kontoyiannis DP (2003) Common community respiratory viruses in patients with cancer: more than just "common colds". Cancer 97:2576-2587

10. Anaissie EJ, Mahfouz TH, Aslan T et al (2004) The natural history of respiratory syncytial virus infection in cancer and transplant patients: implications for management. Blood 103:1611-1617

11. Vento S, Cainelli F, Temesgen Z (2008) Lung infections after cancer chemotherapy. Lancet Oncol 9:982-992

12. Francisci D, Labianca R, Roila F (2010) Prevention and treatment of pandemic influenza in cancer patients. Ann Oncol 21:2301-2303

13. Ison MG (2011) Epidemiology, prevention, and management of influenza in patients with hematologic malignancy. Infect Disord Drug Targets 11:34-39

14. Meerveld-Eggink A, de Weerdt O, van der Velden AM et al (2011) Response to influenza virus vaccination during chemotherapy in patients with breast cancer. Ann Oncol 22:2031-2035

15. Eliakim-Raz N, Vinograd I, Zalmanovici Trestioreanu A, Leibovici L, Paul M (2013) Influenza vaccines in immunosuppressed adults with cancer. Cochrane Database Syst Rev 10:CD008983

16. Saral R, Burns WH, Prentice HG (1984) Herpes virus infections: clinical manifestations and therapeutic strategies in immunocompromised patients. Clin Haematol 13:645-660

17. Anderson H, Scarffe JH, Sutton RN, Hickmott E, Brigden D, Burke C (1984) Oral acyclovir prophylaxis against herpes simplex virus in non-Hodgkin lymphoma and acute lymphoblastic leukaemia patients receiving remission induction chemotherapy. A randomised double blind, placebo controlled trial. Br J Cancer 50:45-49

18. Bergmann OJ, Mogensen SC, Ellermann-Eriksen S, Ellegaard J (1997) Acyclovir prophylaxis and fever during remissioninduction therapy of patients with acute myeloid leukemia: a randomized, double-blind, placebo-controlled trial. J Clin Oncol Off J Am Soc Clin Oncol 15:2269-2274

19. Yahav D, Gafter-Gvili A, Muchtar E et al (2009) Antiviral prophylaxis in haematological patients: systematic review and meta-analysis. Eur J Cancer 45:3131-3148

20. Styczynski J, Reusser P, Einsele H et al (2009) Management of HSV, VZV and EBV infections in patients with hematological malignancies and after SCT: guidelines from the Second European Conference on Infections in Leukemia. Bone Marrow Transplant 43:757-770

21. Engelhard D, Mohty B, de la Camara R, Cordonnier C, Ljungman P (2013) European guidelines for prevention and management of influenza in hematopoietic stem cell transplantation and leukemia patients: summary of ECIL-4 (2011), on behalf of ECIL, a joint venture of EBMT, EORTC, ICHS, and ELN. Transpl Infect Dis $15: 219-232$

22. Yeo W, Chan PK, Zhong S et al (2000) Frequency of hepatitis B virus reactivation in cancer patients undergoing cytotoxic chemotherapy: a prospective study of 626 patients with identification of risk factors. J Med Virol 62:299-307

23. Yeo W, Zee B, Zhong S et al (2004) Comprehensive analysis of risk factors associating with Hepatitis B virus (HBV) reactivation in cancer patients undergoing cytotoxic chemotherapy. Br J Cancer 90:1306-1311

24. Huang YW, Chung RT (2012) Management of hepatitis B reactivation in patients receiving cancer chemotherapy. Ther Adv Gastroenterol 5:359-370

25. Chen CY, Huang SY, Cheng A et al (2015) High risk of hepatitis B reactivation among patients with acute myeloid leukemia. PLoS One 10:e0126037

26. Yeo W, Chan PK, Hui P et al (2003) Hepatitis B virus reactivation in breast cancer patients receiving cytotoxic chemotherapy: a prospective study. J Med Virol 70:553-561

27. Yun J, Kim KH, Kang ES et al (2011) Prophylactic use of lamivudine for hepatitis B exacerbation in post-operative breast cancer patients receiving anthracycline-based adjuvant chemotherapy. Br J Cancer 104:559-563

28. Tur-Kaspa R, Burk RD, Shaul Y, Shafritz DA (1986) Hepatitis B virus DNA contains a glucocorticoid-responsive element. Proc Natl Acad Sci U S A 83:1627-1631

29. Cheng AL, Hsiung CA, Su IJ et al (2003) Steroid-free chemotherapy decreases risk of hepatitis B virus (HBV) reactivation in HBVcarriers with lymphoma. Hepatology 37:1320-1328

30. Reddy KR, Beavers KL, Hammond SP, Lim JK, Falck-Ytter YT (2015) American Gastroenterological Association I. American Gastroenterological Association Institute guideline on the prevention and treatment of hepatitis B virus reactivation during immunosuppressive drug therapy. Gastroenterology 148:215-219, quiz e16-7

31. Marinone C, Mestriner M (2011) HBV disease: HBsAg carrier and occult B infection reactivation in haematological setting. Dig Liver Dis 43(Suppl 1):S49-S56

32. O'Brien SN, Blijlevens NM, Mahfouz TH, Anaissie EJ (2003) Infections in patients with hematological cancer: recent developments. Hematology 438-72

33. Samonis G, Kontoyiannis DP (2001) Infectious complications of purine analog therapy. Curr Opin Infect Dis 14:409-413

34. Anaissie EJ, Kontoyiannis DP, O'Brien S et al (1998) Infections in patients with chronic lymphocytic leukemia treated with fludarabine. Ann Intern Med 129:559-566

35. Keating GM (2010) Rituximab: a review of its use in chronic lymphocytic leukaemia, low-grade or follicular lymphoma and diffuse large B-cell lymphoma. Drugs 70:1445-1476

36. Held G, Poschel V, Pfreundschuh M (2006) Rituximab for the treatment of diffuse large B-cell lymphomas. Expert Rev Anticancer Ther 6:1175-1186

37. Leung C, Tsoi E, Burns G, Sievert W (2011) An argument for the universal prophylaxis of hepatitis B infection in patients receiving rituximab: a 7-year institutional experience of hepatitis screening. Oncologist 16:579-584

38. Tsutsumi Y, Yamamoto Y, Tanaka J, Asaka M, Imamura M, Masauzi N (2009) Prevention of hepatitis B virus reactivation under rituximab therapy. Immunotherapy 1:1053-1061

39. Mendez-Navarro J, Corey KE, Zheng H et al (2011) Hepatitis B screening, prophylaxis and re-activation in the era of rituximabbased chemotherapy. Liver Int 31:330-339

40. Evens AM, Jovanovic BD, Su YC et al (2011) Rituximabassociated hepatitis B virus (HBV) reactivation in lymphoproliferative diseases: meta-analysis and examination of FDA safety reports. Ann Oncol 22:1170-1180

41. Carson KR, Focosi D, Major EO et al (2009) Monoclonal antibodyassociated progressive multifocal leucoencephalopathy in patients treated with rituximab, natalizumab, and efalizumab: a Review from the Research on Adverse Drug Events and Reports (RADAR) Project. Lancet Oncol 10:816-824

42. Villa D, Gubbay J, Sutherland DR et al (2013) Evaluation of 2009 pandemic H1N1 influenza vaccination in adults with lymphoid malignancies receiving chemotherapy or following autologous stem cell transplant. Leuk Lymphoma 54:1387-1395

43. Issa NC, Baden LR (2012) Current issues in vaccines for adult patients with hematologic malignancies. J Natl Compr Cancer Netw 10:1447-1454, quiz 54

44. Buensalido JA, Chandrasekar PH (2014) Prophylaxis against hepatitis $B$ reactivation among patients with lymphoma receiving rituximab. Expert Rev Anti-Infect Ther 12:151-154

45. European Association For The Study Of The L (2012) EASL clinical practice guidelines: management of chronic hepatitis B virus infection. J Hepatol 57:167-185

46. Artz AS, Somerfield MR, Feld JJ et al (2010) American Society of Clinical Oncology provisional clinical opinion: chronic hepatitis B virus infection screening in patients receiving cytotoxic 
chemotherapy for treatment of malignant diseases. J Clin Oncol Off J Am Soc Clin Oncol 28:3199-3202

47. Dreyling M, Ghielmini M, Marcus R, Salles G, Vitolo U, Group EGW (2011) Newly diagnosed and relapsed follicular lymphoma: ESMO clinical practice guidelines for diagnosis, treatment and follow-up. Ann Oncol 22(Suppl 6):vi59-vi63

48. McNamara C, Davies J, Dyer M et al (2012) Guidelines on the investigation and management of follicular lymphoma. Br J Haematol 156:446-467

49. Zelenetz AD, Abramson JS, Advani RH et al (2011) NonHodgkin's lymphomas. J Natl Compr Cancer Netw 9:484-560

50. Buch MH, Aletaha D, Emery P, Smolen JS (2011) Reporting of long-term extension studies: lack of consistency calls for consensus. Ann Rheum Dis 70:886-890

51. Weinbaum CM, Mast EE, Ward JW (2009) Recommendations for identification and public health management of persons with chronic hepatitis B virus infection. Hepatology 49:S35-S44

52. Buch MH, Smolen JS, Betteridge N et al (2011) Updated consensus statement on the use of rituximab in patients with rheumatoid arthritis. Ann Rheum Dis 70:909-920

53. Zurawska U, Hicks LK, Woo G et al (2012) Hepatitis B virus screening before chemotherapy for lymphoma: a costeffectiveness analysis. J Clin Oncol Off J Am Soc Clin Oncol 30: 3167-3173

54. Kumar A, Younes A (2014) Role of CD30 targeting in malignant lymphoma. Curr Treat Options in Oncol. doi:10.1007/s11864-0140275-7

55. Cornely OA, Ullmann AJ, Karthaus M (2004) Opportunistic infections after treatment with monoclonal antibodies. Wien Med Wochenschr 154:209-217

56. Engelhardt M, Terpos E, Kleber M et al (2014) European myeloma network recommendations on the evaluation and treatment of newly diagnosed patients with multiple myeloma. Haematologica 99: 232-242

57. Chanan-Khan A, Sonneveld P, Schuster MW et al (2008) Analysis of herpes zoster events among bortezomib-treated patients in the phase III APEX study. J Clin Oncol 26:4784-4790

58. Swaika A, Paulus A, Miller KC et al (2012) Acyclovir prophylaxis against varicella zoster virus reactivation in multiple myeloma patients treated with bortezomib-based therapies: a retrospective analysis of 100 patients. J Support Oncol 10:155-159

59. Aoki T, Nishiyama T, Imahashi N, Kitamura K (2011) Efficacy of continuous, daily, oral, ultra-low-dose $200 \mathrm{mg}$ acyclovir to prevent herpes zoster events among bortezomib-treated patients: a report from retrospective study. Jpn J Clin Oncol 41:876-881

60. Pour L, Adam Z, Buresova L et al (2009) Varicella-zoster virus prophylaxis with low-dose acyclovir in patients with multiple myeloma treated with bortezomib. Clin Lymphoma Myeloma 9:151153

61. Vickrey E, Allen S, Mehta J, Singhal S (2009) Acyclovir to prevent reactivation of varicella zoster virus (herpes zoster) in multiple myeloma patients receiving bortezomib therapy. Cancer 115:229-232

62. Casper C, Englund J, Boeckh M (2010) How I treat influenza in patients with hematologic malignancies. Blood 115:1331-1342

63. Rogers JE, Cumpston A, Newton M, Craig M (2011) Onset and complications of varicella zoster reactivation in the autologous hematopoietic cell transplant population. Transpl Infect Dis 13:480484

64. Barton T, Collis T, Stadtmauer E, Schuster M (2001) Infectious complications the year after autologous bone marrow transplantation or peripheral stem cell transplantation for treatment of breast cancer. Clin Infect Dis 32:391-395

65. Holmberg LA, Boeckh M, Hooper H et al (1999) Increased incidence of cytomegalovirus disease after autologous CD34-selected peripheral blood stem cell transplantation. Blood 94:4029-4035
66. Weissinger F, Auner HW, Bertz H et al (2012) Antimicrobial therapy of febrile complications after high-dose chemotherapy and autologous hematopoietic stem cell transplantation - Guidelines of the Infectious Diseases Working Party (AGIHO) of the German Society of Hematology and Oncology (DGHO). Ann Hematol 91: 1161-1174

67. Novero A, Ravella PM, Chen Y, Dous G, Liu D (2014) Ibrutinib for B cell malignancies. Exp Hematol Oncol 3:4

68. Robak T, Robak P (2013) BCR signaling in chronic lymphocytic leukemia and related inhibitors currently in clinical studies. Int Rev Immunol 32:358-376

69. Teplinsky E, Cheung D, Weisberg I et al (2013) Fatal hepatitis B reactivation due to everolimus in metastatic breast cancer: case report and review of literature. Breast Cancer Res Treat 141:167172

70. Cervantes F, Vannucchi AM, Kiladjian JJ et al (2013) Three-year efficacy, safety, and survival findings from COMFORT-II, a phase 3 study comparing ruxolitinib with best available therapy for myelofibrosis. Blood 122:4047-4053

71. Wang ML, Blum KA, Martin P, et al (2015) Long-term follow-up of MCL patients treated with single-agent ibrutinib: updated safety and efficacy results. Blood

72. D'Aniello C, Maruzzo M, Basso U (2013) Prevention of hepatitis B virus reactivation with lamivudine in a patient with advanced renal cell carcinoma treated with everolimus. Am J Ther

73. Sandherr M (2011) Antiviral agents in patients with haematological malignancies and acute respiratory failure. In: Azoulay E (ed) Pulmonary involvment in patients with haematological malignancies. Springer Verlag, Berlin, pp 589-595

74. Eisen D, Essell J, Broun ER, Sigmund D, DeVoe M (2003) Clinical utility of oral valacyclovir compared with oral acyclovir for the prevention of herpes simplex virus mucositis following autologous bone marrow transplantation or stem cell rescue therapy. Bone Marrow Transplant 31:51-55

75. Warkentin DI, Epstein JB, Campbell LM et al (2002) Valacyclovir versus acyclovir for HSV prophylaxisin neutropenic patients. Ann Pharmacother 36:1525-1531

76. RKI Sa. Empfehlungen der Ständigen Impfkommission (STIKO) am Robert Koch-Institut. Epidemiologisches Bulletin 2013; Nr. 34: 313-44

77. Pedrazzoli P, Baldanti F, Donatelli I et al (2014) Vaccination for seasonal influenza in patients with cancer: recommendations of the Italian Society of Medical Oncology (AIOM). Ann Oncol 25:12431247

78. Nordoy T, Aaberge IS, Husebekk A et al (2002) Cancer patients undergoing chemotherapy show adequate serological response to vaccinations against influenza virus and Streptococcus pneumoniae. Med Oncol 19:71-78

79. Pollyea DA, Brown JM, Horning SJ (2010) Utility of influenza vaccination for oncology patients. J Clin Oncol 28:2481-2490

80. Mazza JJ, Yale SH, Arrowood JR et al (2005) Efficacy of the influenza vaccine in patients with malignant lymphoma. Clin Med Res 3:214-220

81. Rousseau B, Loulergue P, Mir O et al (2012) Immunogenicity and safety of the influenza A H1N1v 2009 vaccine in cancer patients treated with cytotoxic chemotherapy and/or targeted therapy: the VACANCE study. Ann Oncol 23:450-457

82. Lalazar G, Rund D, Shouval D (2007) Screening, prevention and treatment of viral hepatitis B reactivation in patients with haematological malignancies. Br J Haematol 136:699-712

83. Hwang JP, Vierling JM, Zelenetz AD, Lackey SC, Loomba R (2012) Hepatitis B virus management to prevent reactivation after chemotherapy: a review. Support Care Cancer 20:2999-3008

84. Seto WK, Chan TS, Hwang YY et al (2014) Hepatitis B reactivation in patients with previous hepatitis B virus exposure undergoing 
rituximab-containing chemotherapy for lymphoma: a prospective study. J Clin Oncol 32:3736-3743

85. Ling WH, Soe PP, Pang AS, Lee SC (2013) Hepatitis B virus reactivation risk varies with different chemotherapy regimens commonly used in solid tumours. Br J Cancer 108:1931-1935

86. Yeo W, Chan TC, Leung NW et al (2009) Hepatitis B virus reactivation in lymphoma patients with prior resolved hepatitis B undergoing anticancer therapy with or without rituximab. J Clin Oncol 27:605-611

87. Liang R (2009) How I, treat and monitor viral hepatitis B infection in patients receiving intensive immunosuppressive therapies or undergoing hematopoietic stem cell transplantation. Blood 113:3147-3153
88. Huang YH, Hsiao LT, Hong YC et al (2013) Randomized controlled trial of entecavir prophylaxis for rituximabassociated hepatitis B virus reactivation in patients with lymphoma and resolved hepatitis B. J Clin Oncol Off J Am Soc Clin Oncol 31:2765-2772

89. Chen TT, Chiu CF, Yang TY et al (2015) Hepatitis C infection is associated with hepatic toxicity but does not compromise the survival of patients with diffuse large B cell lymphoma treated with rituximab-based chemotherapy. Leuk Res 39:151-156

90. Li HC, Lo SY (2015) Hepatitis C virus: virology, diagnosis and treatment. World J Hepatol 7:1377-1389 